\title{
Design of Hydraulic Pulse Test System based on PLC and HMI
}

\author{
Zehong Wang ${ }^{\mathrm{a}}$, Jungong $\mathrm{Ma}^{\mathrm{b}}$
}

School of Mechanical Engineering and Automation, Beihang University, Beijing 100191, China

abuaamee@163.com, bjgma@buaa.edu.cn

Keywords: Measurement and Control System, Pulse Test, PLC, HMI.

\begin{abstract}
A test and control system for hydraulic pulse test is designed according to the requirement of high temperature pulse endurance test of automotive air conditioning system. The system can control the temperature, pressure and switching frequency. It also has the function of timing detection and fault diagnosis. In this paper, the design process of the test system is introduced in detail from the aspects of the hydraulic system, the software and the hardware of the control system and so on. The system uses the electro hydraulic servo control technology to ensure the accuracy of the test. The friendly man-machine interface makes the operation simple and clear. The test system has been put into use, and the operation process is stable and reliable.
\end{abstract}

\section{Introduction}

With the rapid development of transportation, the number of cars has increased dramatically. The automotive air conditioning parts are important to ensuring driver and passengers comfort. In order to guarantee the service life of the automobile air conditioning, it needs life test under different working conditions [1]. According to the national standard GBT 21361-2008 automotive air conditioner pipeline needs to carry out the pulse life test to detect the tightness of it [2].

Pulse life test has the characteristics of long time consuming and high reliability. Therefore, a high degree of automation and high reliability of the measurement and control system which are combined with hydraulic loading system are needed to realize the function of the hydraulic loading system. The system which is to achieve the mechanical and electrical integration includes the host computer (Kunlun touch screen), the slave machine (Siemens S7-200PLC) as well as the hydraulic system. All operations can be completed in the host computer, including the test parameters, test start and stop, the parameters of real-time display, historical data display, fault diagnosis, etc.

\section{Requirements of the test system}

Basic performance requirements:

(1) Pulse pressure value: high pressure $1-3 \mathrm{MPa}$, low pressure $0.3 \mathrm{MPa}$.

(2) The pulse frequency: $0.50 \sim 3.00 \mathrm{~Hz}$, the default is set to $1.25 \mathrm{~Hz}$.

(3) The test system has oil temperature control system, and the oil temperature can be set. The precision of temperature control is $\pm 5^{\circ} \mathrm{C}$, and the default is set to $80 \pm 5^{\circ} \mathrm{C}$.

(4) Proportional directional valve is to switch high and low voltage.

(5) Bypass solenoid directional valve is to switch high and low voltage on manual and low frequency state.

\section{System design}

\subsection{Hydraulic system design.}

The hydraulic system principle of the hydraulic pulse test of the automobile air conditioning is shown in Figure 1. 


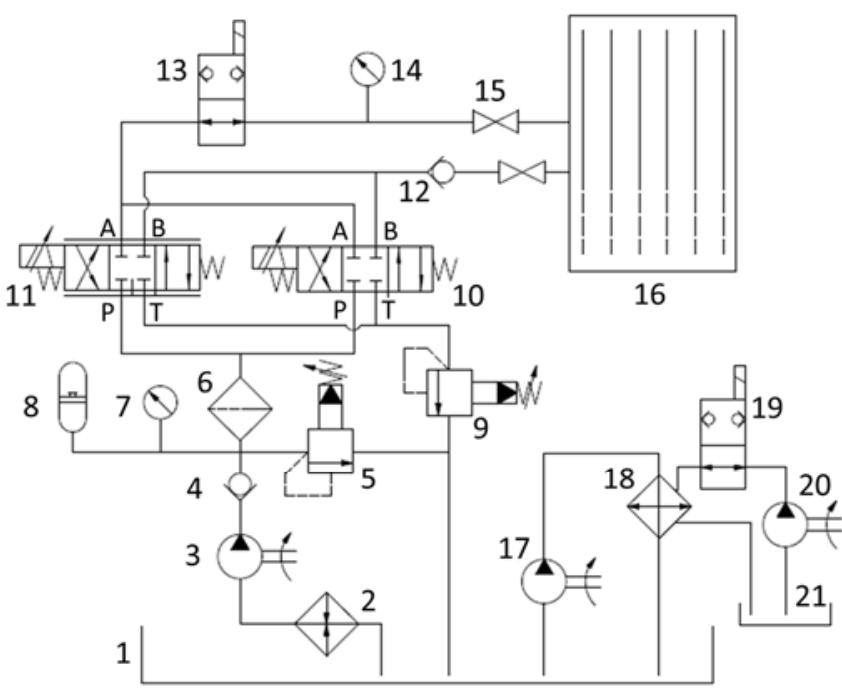

\footnotetext{
1-oil box 2-heater 3-main pump 4-one-way valve 1 5-Proportional relief valve 1 6- oil filter 7- Pressure gauge 1 8-accumulator 9- Proportional relief valve 2 10- Solenoid directional valve 11-proportional directional valve 12-one-way valve 2 13-Electromagnetic ball valve $1 \quad$ 14-Pressure gauge $2 \quad 15$-Globe valve 16- Test product 17-Circulating pump 18-cooler 19-Electromagnetic ball valve 2 20- Water pump 21- water box
}

Fig. 1 Schematic diagram of hydraulic system

The hydraulic system is the terminal unit of the whole test system, the main function of it is to provide power and pulse loading, and each of which is controlled by PLC. Pressure and other data are displayed on the HMI.

The whole hydraulic circuit mainly consists of power components (pump), control components (valve) and the sample. There are 3 pumps in the hydraulic system, and NO.3 of them is the main pump which provides the hydraulic power for the loading system. NO. 17 is a circulating pump which can help oil circulation in the tank. NO. 20 is the water pump which works in the cooling process. Hydraulic system loading pressure switching is mainly due to NO.10 solenoid valve or NO.11 proportional valve. NO.10 electromagnetic valve is under working condition and NO.11 proportional valve in the middle position on low frequency $(0-1 \mathrm{~Hz})$ state. NO.11 proportional valve is under working condition and NO.10 electromagnetic valve in the middle position on low frequency $(1-3 \mathrm{~Hz})$ state. Because the solenoid directional control valve which responds slowly is cheap, and the proportional directional control valve which responds quickly is expensive. The high pressure value of the load which is the inlet pressure of the circuit is set by adjusting NO.5 proportional relief valve. And the low pressure value which is the outlet pressure of the circuit is set by adjusting NO.9 proportional relief valve. NO.8 accumulator is used to absorb the pressure pulsation in the hydraulic circuit [3].

Test loading principle: the initial temperature (room temperature) of oil is lower than the set temperature $\left(80^{\circ} \mathrm{C}\right.$ ) when the machine starts, so the heater and a circulating pump will start automatically. Then the relief valve can be set according to the load pressure. The main pump starts when the oil temperature is heated to the set temperature. At the same time, the system will self-check. If the test cycle conditions are in accordance with test conditions, the value begins switching back and forth. Pulse loading is divided into two parts including high pressure and low pressure loading. The A port of the directional control valve communicates with the $\mathrm{P}$ port when it is high pressure loading, and NO.12 ball valve is cut-off. Therefore, the pressure is decided by the overflow valve of NO.5 entrance. The B port of the reversing valve communicates with the $\mathrm{P}$ port when it is low pressure loading, and NO.12 ball valve is conducting state. At this point, the pressure of the hydraulic circuit is determined by the number 9 relief valve. When the number of trials reaches 2000 times, NO.13 solenoid valve gets power aiming to form a closed loop [4]. The pressure is held for 10 seconds to observe whether there is a leak. NO.13 solenoid valve loses power and the test continues if there is no leakage 10 seconds later. The $\mathrm{B}$ port of the reversing valve is connected with the $\mathrm{P}$ port for 5 seconds when the number of trials reaches 20001 times, and the hydraulic oil in the sample will be 
completely recycled. The NO.15 valve can be closed to replace the test piece when the test is finished or the leakage occurs.

\subsection{Hardware design of measurement and control system}

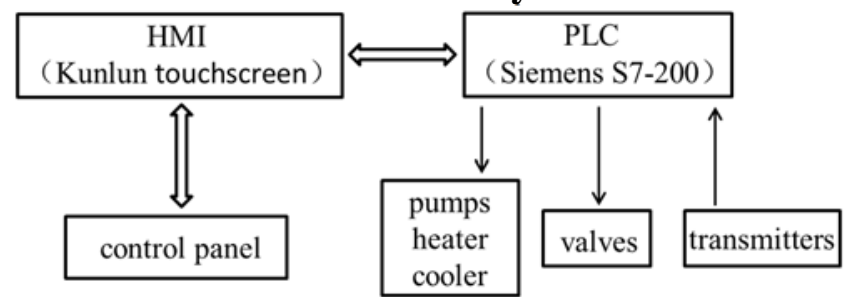

Fig. 2 Hardware structure of measurement and control system

HMI: the host computer has a friendly man-machine interface, including basic parameters setting, test status setting, test status judgment, real-time status display, historical data storage and fault diagnosis and so on. HMI gets digital signals and analog signals from the PLC. Analog signals are transformed into numbers in accordance with the corresponding ratio of conversion. Digital signals of oil filter plugging, leakage, overrun alarm correspond to the HMI in the fault diagnosis interface. The main interface is shown in figure 3 [5].

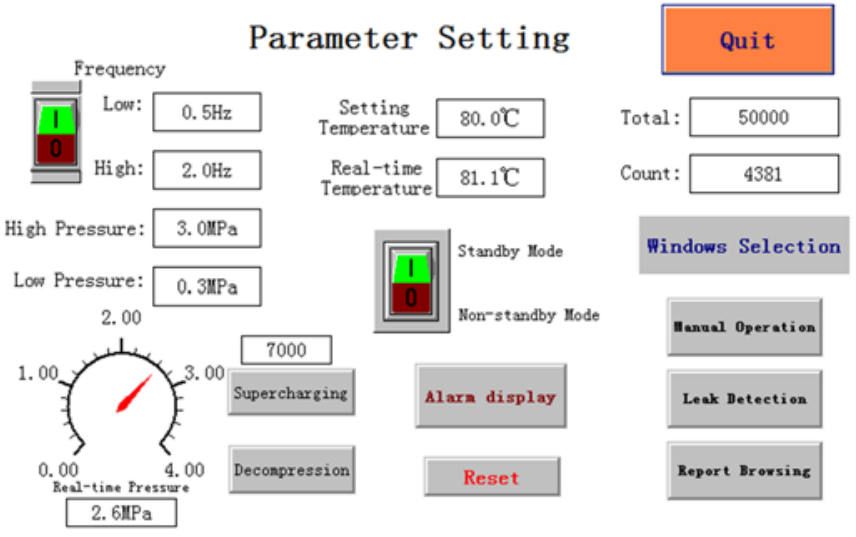

Fig. 3 Main interface of HMI

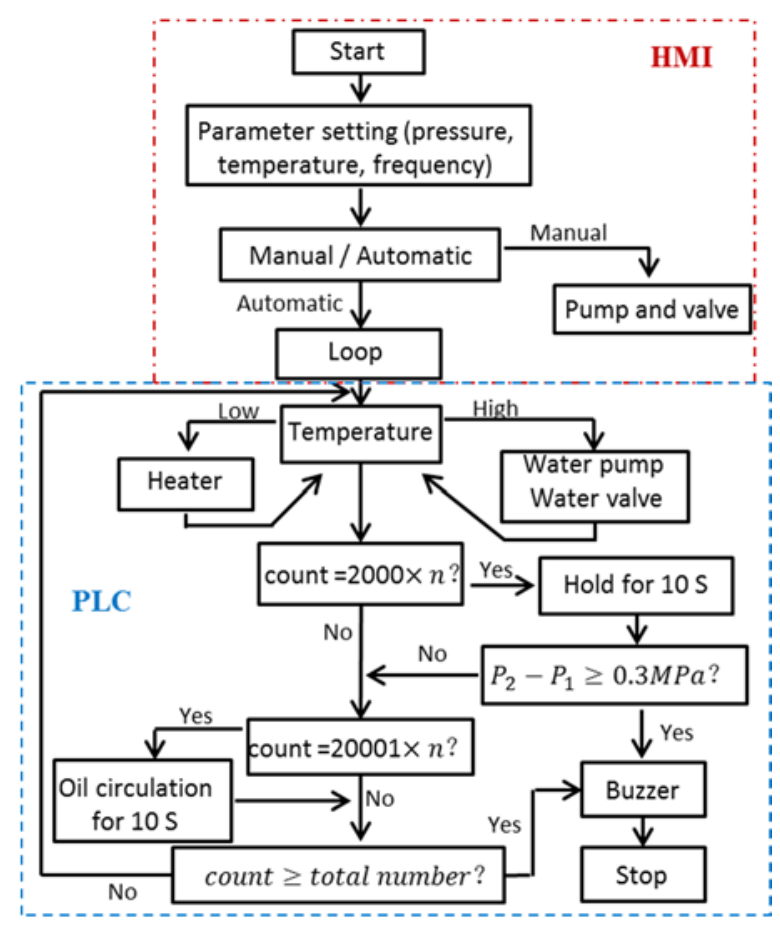

Fig. 4 Block diagram of the software. 
PLC: PLC consists of S7-200 (CPU224XP) and EM235 analog module composition, including 5 channels of analog input, 2 channels of analog output, 10 channels of digital output and 16 channels of digital input. PLC's main function is to collect all sensor signals directly and upload data to the HMI. It receives the HMI instructions to control the start and stop of pumps and the opening of valves according to a series of logical control, including timing, counting, cycle, etc. PLC communicates with HMI through RS485 [6].

\subsection{Software design of measurement and control system}

The software design of the measurement and control system is mainly divided into two parts, the HMI corresponding MCGS configuration program and the Siemens PLC corresponding to Step7 program. The basic logic frame of the software design is shown in Figure 4 [7].

\section{Summary}

In this paper, electro-hydraulic servo control technology and friendly HMI are applied in the design of hydraulic pulse test system. Compared with the traditional air conditioning life test, the system improves the control precision, and greatly improves the automation degree, which not only ensures the quality of the test drive, but also drives the running efficiency. Operation for the machine is simple and readable, so that ordinary workers are able to quickly grasp the test operation. In this system, the fault diagnosis, power down protection, emergency stop and so on are fully designed to ensure the safety of the test work. PLC's high reliability in harsh conditions is the most important part of the test to ensure the stability of the operation for a long time. Now the test bench has been delivered. Now a number of automotive air conditioning products life tests have been completed, and the performance of their work has been fully affirmed.

\section{References}

[1] Hanwu Li, Yuyang Zhao, Chunpeng Yu. Research of Automobile Air-conditioner Test Technology. Journal of Heilongjiang Institute of Technology. Vol. 19 (2005) No. 1, p. 48-50.

[2] Standardization Administration of the People's Republic of China. GBT 21361-2008 Technical Requirements for Automotive Air Conditioners. Standards Press of China, 2008, p. 10-12.

[3] Zhanlin Wang. Modern Hydraulic Control . China Machine Press, 1997, p. 55-56.

[4] Weisong Liu, Wei Ren. Development of Multifunctional Automobile Air Conditioning Test Bed. Public Communication of Science \& Technology. Vol. 16 (2013) No. 2, p. 131-133.

[5] Jingbo Zhao, Lun A. Study SIEMENS S7-200PLC From Zero. China Machine Press, 2013, p. 166-181.

[6] Zhujue Tong, Xiaoling Wang. Design of an Impulse Pressure Test System Including Double Accumulators Based on PLC. Machine Tool \& Hydraulics. Vol. 42 (2014) No. 20, p. 105-108.

[7] Xiangmin Li, Huilan Zhang. The Hydraulic System Design of Hydraulic Impulse Synthesize Test. Chinese Hydraulics \& Pneumatics. Vol. 22 (2004) No. 2, p. 11-13. 